\title{
CORRELAÇÃO ENTRE VARIÁVEIS DE CRESCIMENTO DO FRUTO DA MANGUEIRA 'TOMMY ATKINS'
}

\author{
Relationship of fruit growth variables of 'Tommy Atkins' mango \\ Patrícia Lígia Dantas de Morais ${ }^{1}$, Heloisa Almeida Cunha Filgueiras ${ }^{2}$, \\ João Licínio Nunes de Pinho ${ }^{3}$, Ricardo Elesbão Alves ${ }^{2}$
}

\begin{abstract}
RESUMO
Estudos sobre o fruto da mangueira geralmente são realizados por métodos destrutivos, os quais modificam o sistema fisiológico que alimenta os frutos remanescentes, em decorrência de alterações na relação fonte dreno da panícula. Objetivou-se com este trabalho estudar o grau de correlação entre variáveis do crescimento, a fim de determinar métodos não-destrutivos capazes de definir o estádio de desenvolvimento da manga. O experimento foi conduzido em pomar comercial da Empresa FRUNORTE, em Assu-RN. Foram marcadas 200 panículas de 200 árvores selecionadas aos 32 dias após o inicio do pleno florescimento. Realizaram-se medições dos diâmetros longitudinais, ventrais e dorsais dos frutos na planta. Foram retiradas amostras de 20 frutos/tratamento com idades de 32, 46, 60, 74, 82, 89, 96 e 103 dias após o florescimento pleno, e avaliados quanto ao peso da massa fresca (MF) e seca (MS) e volume. Os diâmetros longitudinais, ventrais e dorsais foram medidos com paquímetro digital e os resultados foram utilizados para o cálculo do produto dos diâmetros. A MF e volume foram as variáveis que apresentaram maior grau de correlação. As correlações da MF com o produto dos diâmetros e do volume do fruto com o produto dos diâmetros também foram altas. A MS correlacionou-se com o produto dos diâmetros, apresentando valor de $\mathrm{r}=0,94$. Com esses dados sugere-se que se pode estimar a MF e a MS dos frutos mediante métodos não-destrutivos, como a determinação do volume e o produto dos diâmetros.
\end{abstract}

Termos para indexação: Mangífera indica L., desenvolvimento, métodos não destrutivos.

\begin{abstract}
Usually, studies on the development of mango fruits are made by destructive methods, which modify the physiologic system feeding the remaining fruits, due to alterations in the source and sink relationship. The objective of the work was to study the relationship among growth variables, in order to establish a non-destructive method capable of defining fruit development stages. The experiment was carried out in a commercial orchard at the FRUNORTE farm, in Assu-RN. The fruits were harvested from 200 trees and had their fresh (FM) and dry matter (DM) weights, volume, and dorsal, ventral and longitudinal diameters evaluated at 32, 46, 60,74, 82, 89, 96, and 103 days after full bloom. The products of the longitudinal, ventral and dorsal diameters were used as a new variable. Correlation analyses showed a high coefficient regarding the variables FM and volume. High correlation coefficients were also found between FM and volume against product of diameters. A correlation coefficient (r) of 0,94 was found between DM and the product of diameters. Therefore, it can be concluded that during the development of fruit, FM and FD could be estimated through non-destructives methods from determination of volume or the product of the fruit diameters.
\end{abstract}

Index terms: Mangífera indica L., development, non-destructive method.

(Recebido para publicação em 11 de setembro de 2003 e aprovado em 15 de outubro de 2003)

\section{INTRODUÇÃO}

O fruto da mangueira é uma drupa carnosa, que varia consideravelmente em tamanho, forma, coloração, presença de fibra, aroma e sabor (SILVA, 1996).

$\mathrm{O}$ crescimento do fruto da mangueira apresenta padrão sigmoidal, caracterizado por um rápido aumento até aproximadamente 12 semanas após a fertilização e depois por um aumento mais lento e gradual até pouco antes da maturidade completa. De acordo com as mudanças metabólicas, a sua ontogenia pode ser separada em quatro estádios (juvenil, adolescente, climatérico e senescência) mais ou menos bem definidos (MEDINA, 1981).

Kader (2002) informa que a qualidade do fruto não depende apenas dos processos fisiológicos que

\footnotetext{
1. Doutoranda em Fisiologia Vegetal - Universidade Federal de Lavras/UFLA - Caixa Postal 37 - 37200-000 - Lavras, MG. plmorais@ufla.br

2. Pesquisadores da Embrapa Agroindústria Tropical - Caixa Postal 3761 - 60511-110 - Fortaleza, CE.

3. Professor do Departamento de Fitotecnia -Centro de Ciências Agrárias/Universidade Federal do Ceará - 60511-110 - Fortaleza, CE.
} 
ocorrem durante o amadurecimento, mas também dos que acontecem durante todo o seu desenvolvimento. As condições climáticas e as práticas culturais às quais os frutos são submetidos durante o seu crescimento apresentam grande influência no seu processo de desenvolvimento, podendo acelerar ou retardar a sua colheita (LEE e KADER, 2000).

O ponto de colheita dos frutos é um fator decisivo na qualidade final do produto. Vários métodos baseados em indicadores fisiológicos têm sido utilizados para determinar esse período de desenvolvimento da manga, no qual ela pode ser colhida sem prejudicar a sua qualidade final e com vida útil adequada para seu transporte e comercialização (ROCHA et al., 2001).

Na Região Nordeste do Brasil, onde a mangueira tem grande importância econômica, há carência de informações sobre o seu crescimento, fatores que influenciam o seu desenvolvimento e ajuste de indicadores do ponto de colheita. Os estudos sobre o desenvolvimento da manga são realizados por métodos destrutivos, os quais modificam o sistema fisiológico que alimenta os frutos remanescentes, em decorrência de alterações na relação fonte/dreno da panícula.

Castro Neto e Reinhardt (2003) determinaram um método não-destrutivo para determinações das massas secas e frescas ao longo do desenvolvimento de manga 'Haden' cultivada no Estado de Pernambuco. No entanto, indicadores fisiológicos são influenciados pelas condições de cultivo e cultivar, não existindo um método que possa ser generalizado, tornando-se necessário o ajuste da metodologia para cada cultivar e região específica.

Objetivou-se com este trabalho estudar o grau de correlação entre variáveis do crescimento, a fim de determinar métodos não-destrutivos capazes de definir o estádio de desenvolvimento da manga, sem, contudo, retirá-lo da planta.

\section{MATERIAL E MÉTODOS}

O experimento foi realizado em área de produção comercial da Empresa FRUNORTE Ltda, localizada no município de Assu-RN. O clima dessa região é classificado como semi-árido, quente e seco Bswh' (Köppen), com temperatura máxima de $33^{\circ} \mathrm{C}$ e mínima de $29^{\circ} \mathrm{C}$. Os meses de junho e julho são os mais frios e dezembro, o mais quente. A precipitação pluvial média anual é de 500 a $600 \mathrm{~mm}$ e a insolação média é de 236 horas mensais, podendo ultrapassar 2800 horas anuais (BRASIL, 1992). O solo da área experimental é um latossolo amarelo distrófico com textura areno-argilosa. No pomar utilizado, foram realizadas seis induções florais, adubações de fundação com gesso e foliar com micronutrientes, aplicações de inseticidas e fungicidas e todas as práticas culturais usuais da fazenda. $\mathrm{O}$ suprimento hídrico foi feito de acordo com o cronograma de irrigação da Empresa, obedecendo aos estádios de desenvolvimento da cultura.

Foram selecionadas cerca de 200 árvores de 8 anos de idade, dentro de uma área de plantio comercial. Nessas, foram marcadas 200 panículas, 32 dias após o inicio do florescimento pleno, contendo frutos com diâmetro longitudinal em torno de $5,0 \mathrm{~cm}$. O período de observação do desenvolvimento do fruto foi de 03 de fevereiro a 13 de abril de 2000.

A cada 15 dias, foram realizadas medições dos diâmetros longitudinais, ventrais e dorsais dos frutos na planta, e uma amostra de 20 frutos era retirada e transportada no mesmo dia da colheita para o Laboratório de Pós-colheita da Embrapa Agroindústria Tropical (Fortaleza-CE). Os frutos foram, então, avaliados para massa fresca e volume e, em seguida, cortados para a determinação da massa seca. Esse procedimento foi realizado em frutos com idades de 32, 46, 60, 74, 82, 89, 96 e 103 dias depois de iniciada a floração plena.

A massa dos frutos foi obtida utilizando-se balança semi-analítica e os resultados foram expressos em gramas. $\mathrm{O}$ volume foi determinado pelo volume de água deslocado pelo fruto, o qual foi medido com provetas graduadas de 100, 200, 500, 1000 e $2000 \mathrm{~mL}$, conforme o estádio de desenvolvimento do fruto, e os resultados foram expressos em $\mathrm{cm}^{3}$. Os diâmetros longitudinais, ventrais e dorsais foram medidos com paquímetro digital e os resultados foram utilizados para o cálculo do produto dos diâmetros, expresso em $\mathrm{cm}^{3}$. Para determinação da matéria seca, as amostras foram secas em estufa com circulação forçada de ar a $60^{\circ} \mathrm{C}$ e os resultados expressos em gramas. 
Os coeficientes de correlação foram determinados utilizando o programa estatístico SAS (Statistic Analysis System), ao longo do desenvolvimento do fruto entre massa seca e massa fresca com o volume e produto dos diâmetros.

\section{RESULTADOS E DISCUSSÃO}

Massa fresca e volume foram as variáveis que apresentaram maior grau de correlação (Figura 1). As correlações da massa fresca com o produto dos diâmetros e do volume do fruto com o produto dos diâmetros também foram altas. A massa seca correlacionou-se com o produto dos diâmetros apresentando valor de $r=0,94$. Com esses resultados infere-se que se pode estimar a massa seca e a massa fresca por meio de métodos nãodestrutivos, como a determinação do volume e/ou o produto dos diâmetros.

Resultados semelhantes com essa mesma metodologia foram obtidos por Castro Neto e Reinhardt (2003) para manga 'Haden' cultivada no Estado de Pernambuco. Esses pesquisadores também observaram que, após 55 dias da floração plena, houve um decréscimo da massa fresca, causado possivelmente por uma redução do conteúdo de água do fruto, em decorrência de uma prática comumente usada entre os produtores, que é a suspensão da irrigação para aumentar o conteúdo de sólidos solúveis do fruto e antecipar a colheita, sugerindo que essa prática estaria contribuindo negativamente para uma redução da massa fresca do produto.

Filgueiras et al. (2002) também constataram, em manga 'Tommy Atkins' cultivada no Estado do
Piauí, que a massa seca e fresca podem ser estimadas pelo volume ou produtos dos diâmetros. Dessa forma, pode-se observar a confiabilidade do método, independente da região de cultivo da manga e da cultivar.

Neste experimento, também foi possível determinar a gravidade específica do fruto, considerado um índice de maturidade não-destrutivo. Os frutos com 89 e 103 dias do florescimento pleno apresentaram gravidade específica dentro da faixa de 1,0 a 1,02. Valores semelhantes a esses foram constatados por Kapse e Katrodia (1997) em mangas 'Kesar' em estádio de desenvolvimento adequado para a colheita. Esses resultados atestam a eficiência do método utilizado neste trabalho para determinar o ponto de colheita, pois a colheita dos frutos da cultivar Tommy Atkins costuma ser realizada no período de 89 a 103 dias do florescimento pleno.

Constatou-se em estudos sobre o desenvolvimento do fruto da cultivar Ubá que o período final de desenvolvimento (105 a 168 dias) contribuiu com quase metade do acréscimo da matéria seca, com pequeno aumento no diâmetro do fruto, indicando enchimento do mesocarpo. Nesse período, o fruto alcança o seu comprimento definitivo e aumenta a relação sólidos solúveis totais/acidez total titulável (Moraes et al., 2000). Mediante os resultados obtidos neste trabalho, é possível determinar o período em que o fruto alcança o seu comprimento definitivo e começa a desenvolver os processos metabólicos do amadurecimento, sem, contudo, retirá-lo da planta e mudar o sistema fisiológico que alimenta os frutos remanescentes. 

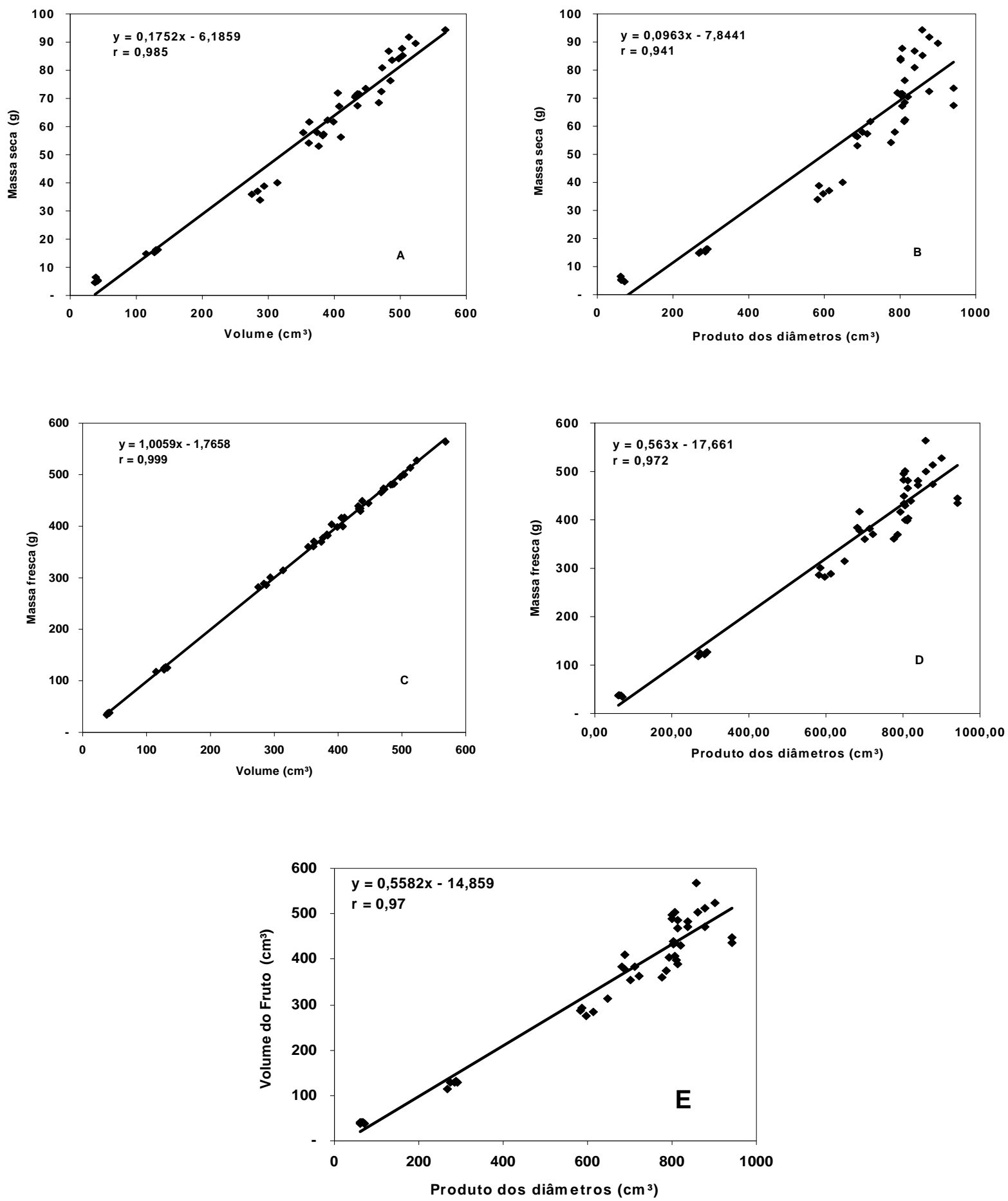

FIGURA 1 - Estudos de correlação: Massa seca (MS) x Volume do fruto (A); MS x Produto dos diâmetros (B); Massa fresca x Volume do fruto (C); Massa fresca x Produto dos diâmetros (D); Volume do fruto x Produto dos diâmetros (E) durante o desenvolvimento de mangas 'Tommy Atkins'. Fortaleza - CE, 2000. 


\section{CONCLUSÃO}

A massa seca e a massa fresca da manga 'Tommy Atkins' podem ser estimadas com precisão a partir do volume ou produto dos diâmetros do fruto.

\section{REFERÊNCIAS BIBLIOGRÁFICAS}

BRASIL. Ministério da Agricultura. Normas climatológicas. Brasília, 1992. 84 p.

CASTRO NETO, M. T. de; REINHARDT, D. H. Relação entre os parâmetros de crescimento do fruto de manga cv. Haden. Revista Brasileira de Fruticultura, Jaboticabal, v. 25, n. 1, p. 36-38, 2003.

FILGUEIRAS, H. A. C.; MORAIS, P. L. D. de; ARAÚJO, E. C. E. A.; VASCONCELOS, L. F. L.; PEREIRA, M. E. C.; ALVES, R. E. Maturation of 'Tommy Atkins' mango grown in Piauí, Brasil. In: INTERNATIONAL MANGO SYMPOSIUM, 7., 2002, Recife-PE. Anais... Recife: [s.n.], 2002. p. 311.

KADER, A. A. Fruits in the global market, In: KNEE, M. Fruit quality and its biological basis. Columbus: Sheffield Academic, 2002. p. 1-14.
KAPSE, B. M.; KATRODIA, J. S. Ripening behaviour of 'Kesar' mangoes in relation to specific gravity. Acta Horticulturae, Wageningen, n. 455, p. 669-677, 1997.

LEE, S. K.; KADER, A. A. Preharvest and Postharvest factors influencing vitamim $\mathrm{C}$ content of horticultural crops. Postharvest Biology and Technology, Amsterdam, v. 20, p. 207-220, 2000.

MEDINA, J. C. Cultura. In: manga. São Paulo: ITAL, 1981. p. 9-227.

MORAES, D. M. de; PUSCHMANN, R.; LOPES, N. F. Respiração e desenvolvimento do fruto de mangueira cv. Ubá. Revista Brasileira de Fruticultura, Jaboticabal, v. 22, p. 37-41, 2000. Edição especial.

ROCHA, R. H. C.; MENEZES, J. B.; MORAIS, E. A.; SILVA, G. G.; AMBRÓSIO, M. M. Q.; ALVES, M. Z. Uso do índice de degradação de amido na determinação da maturidade da manga 'Tommy Atkins'. Revista Brasileira de Fruticultura, Jaboticabal, v. 23, n. 2, p. 302-305, 2001.

SILVA, A. C. da. Botânica da mangueira. In: JOSÉ, A. R. S. Manga: tecnologia de produção e mercado. Vitória da Conquista: UESB, 1996. p. 7-15. 